\title{
PRODUZINDO PROBLEMAS ABERTOS 1 UTILIZANDO TECNOLOGIAS DIGITAIS NO PROCESSO DE FORMAÇÃO INICIAL DE PROFESSORES DE MATEMÁTICA
}

\author{
PRODUCING OPEN PROBLEMS USING DIGITAL TECHNOLOGIES IN THE PROCESS \\ OF INITIAL TRAINING OF MATH TEACHERS
}

\author{
Fabiane Fischer Figueiredo \\ Universidade Luterana do Brasil / fabianefischerfigueiredo@gmail.com \\ Claudia Lisete Oliveira Groenwald \\ Universidade Luterana do Brasil / claudiag@ulbra.onmicrosoft.com
}

\begin{abstract}
Resumo
Neste artigo apresentamos um recorte de um processo formativo realizado no Curso de Extensão Design de problemas com a utilização das Tecnologias Digitais na Educação Matemática, onde dois licenciandos realizaram o Design de um problema aberto com a utilização de Tecnologias Digitais, com o propósito de que o problema fosse proposto em uma prática pedagógica e resolvido por um grupo de alunos do $9^{\circ}$ ano do Ensino Fundamental. Nesse processo formativo, os licenciandos puderam tomar decisões, escolher as Tecnologias Digitais que seriam utilizadas no Design do problema, trocar ideias com outro grupo de licenciandos e com a pesquisadora e planejar a prática pedagógica, determinando os objetivos de ensino e aprendizagem que poderiam ser atingidos com a resolução do problema que produziram. As ações desenvolvidas contribuíram para a formação dos licenciandos, uma vez que houve a oportunidade de experienciar os papéis de designers de problemas e como docentes, possibilitando, também, a discussão, investigação e reflexão sobre essas práticas e potencializando a produção de conhecimentos matemático, metodológico, tecnológico e social, de forma integrada.
\end{abstract}

Palavras-chave: Design de problemas abertos, Formação inicial de professores de Matemática, Resolução de problemas, Tecnologias Digitais.

\section{Abstract}

This article presents a part of a training process developed in the Extension Design Course of Problems with the use of Digital Technologies in the Mathematics Education, where two licensees performed the Design of a problem open using the Digital Technologies. The proposal was that the problem be proposed in a pedagogical practice and solved by a group of 9th grade students of Elementary School. The math graduates were able to make decisions in this training process and thry could to choose the Digital Technologies that would be used in the Design of the problem. It was made a change of

${ }^{1}$ São problemas que "[...] podem ser explorados de diversificadas formas, admitem diferentes soluções e abrem caminhos para o surgimento de novos problemas" (BORBA; SILVA; GADANIDIS, 2014, p. 51). 
ideas with another group of graduates and with the researcher and plan the pedagogical practice. They were determining the teaching and learning objectives that could be reached with the problem they produced. The actions developed by the students can contributed to the training of graduates since they had the opportunity to experience the roles of problem designers and as teachers, enabling discussion, investigation and reflection on these practices and enhancing the production of mathematical and methodological knowledge, technological and social in an integrated way.

Key words: Design of open problems, Initial training of teachers, Problem solving, Digital Technologies.

\section{Introdução}

A formação inicial de professores na contemporaneidade, tanto no âmbito nacional como internacional, vem sendo discutida e (re)pensada devido à necessidade de formar educadores que possuam aptidões para planejar práticas pedagógicas, que proporcionem meios para que os alunos da Educação Básica desenvolvam as capacidades de resolver problemas e utilizar Tecnologias Digitais (IMBERNÓN, 2011; MACHADO; D'AMBROSIO; ARANTES, 2014; MIZUKAMI, 2008; PEREZ, 2012; PERRENOUD, 2002; SHULMAN, 2014). Todavia, para que resultados incidam na Educação Básica, entende-se que é necessário que os futuros professores tenham a oportunidade de produzir conhecimentos teórico-práticos, por meio de experiências pedagógicas que promovam a associação entre a resolução de problemas e o uso das Tecnologias Digitais, como, por exemplo, o Design de problemas matemáticos com a utilização de Tecnologias Digitais.

Essa perspectiva metodológica, quando trabalhada na formação inicial de professores de Matemática, favorece a discussão, a investigação e a reflexão sobre as potencialidades e/ou limitações que o Design e a resolução de problemas, bem como o uso das Tecnologias Digitais podem proporcionar à Educação Matemática (FIGUEIREDO, 2017). Com isso, considera-se que os licenciandos terão a oportunidade de produzir conhecimentos e desenvolver competências que são úteis ao exercício da profissão, como a capacidade de utilizar tecnologias e de planejar atividades que tenham como finalidade a resolução de problemas abertos e contextualizados.

Apresenta-se neste artigo um recorte de um processo formativo, em que uma dupla de licenciandos em Matemática, participantes do Curso de Extensão Design de problemas com a utilização das Tecnologias Digitais na Educação Matemática, realizou o Design de um problema aberto e contextualizado com o uso de Tecnologias Digitais. Esse problema foi proposto e resolvido por um grupo de alunos do $9^{\circ}$ ano do Ensino Fundamental, o que contribuiu para que os licenciandos adquirissem as experiências de designer e de docente, desenvolvessem competências e habilidades e produzissem conhecimentos.

\section{A formação inicial de professores de matemática na contemporaneidade}

A formação inicial, como destaca Imbernón (2011), é a primeira etapa para a aprendizagem profissional, em que devem ser fornecidos meios para a construção do 
conhecimento básico especializado. Para o autor, essa construção envolve o uso de metodologias por parte dos professores formadores, que busquem proporcionar experiências de cooperação e propiciar processos de reflexão sobre a Educação e acerca da realidade social, com o intuito de que competências possam ser desenvolvidas, dentre elas a tomada de decisões, a manifestação de atitudes investigativas, interativas e dialéticas e a capacidade de exercer a tarefa educativa em toda sua complexidade.

Shulman (2014) apresenta dois modelos de formação de professores que podem contribuir com o processo formativo, que são denominados como a base de conhecimento e o processo de raciocínio pedagógico. No primeiro, o autor procura categorizar os conhecimentos que considera necessários para o desempenho da profissão docente: conhecimento do conteúdo a ser ensinado; conhecimento pedagógico geral; conhecimento do currículo; conhecimento pedagógico do conteúdo; conhecimento acerca dos alunos; conhecimento dos contextos educativos; e conhecimento dos objetivos, metas e valores educacionais. No segundo modelo, o autor apresenta um ciclo que envolve as atividades de transformação do conteúdo, o uso de meios de construção, a avaliação do entendimento do aluno, a reflexão sobre a prática pedagógica realizada e a consolidação de uma nova compreensão, com a finalidade de evidenciar o processo de raciocínio e a geração de novas ações pedagógicas.

Perrenoud (2002) destaca que a formação inicial de professores precisa promover meios que permitam a construção de saberes e competências e a aquisição de posturas fundamentais que possam incidir no desempenho da profissão docente. Como sugestões, menciona que os professores formadores devem privilegiar processos formativos que visem à observação, à descrição e à transposição didática a partir de práticas, bem como à prática reflexiva sobre as suas ações nas atividades propostas.

Imbernón (2011), Shulman (2014) e Perrenoud (2002) também defendem a necessidade do processo de reflexão na formação de professores. Inclusive, procuram referenciar a concepção defendida por Schön (2000), que propõe um ensino prático reflexivo, que tenha por finalidade contribuir para a aquisição de competências que tornem os profissionais, em diferentes áreas, criativos e capazes de resolver diferentes situações que possam surgir no exercício da profissão. Para tanto, Schön (2000) sugere que, nos cursos de formação, sejam evidenciados os processos conhecer-na-ação e da reflexão-na-ação, na e sobre a prática, com o propósito de que os futuros profissionais possam construir conhecimento-na-ação e desenvolver capacidades, de acordo com as necessidades requeridas pelo mercado de trabalho.

No cenário educacional contemporâneo, essas concepções defendidas pelos autores $(2000 ; 2002 ; 2011 ; 2014)$ se apresentam nas políticas públicas de formação de professores e nas reformas dos programas dos Cursos de Licenciatura em Matemática e de formação permanente, nas diferentes áreas, tanto nacional como internacionalmente. Essas mudanças vêm sendo impulsionadas pela necessidade de oferecer melhorias nas práticas que são oferecidas nesses cursos e para que os resultados possam ser constatados nas práticas docentes na Educação Básica, Profissional, etc. 
Nesse viés, Fiorentini (2008) afirma que nas últimas três décadas surgiram políticas públicas voltadas à formação inicial de professores, que impõem novos desafios que impactam positiva ou negativamente nas reformas curriculares dos Cursos de Licenciatura em Matemática. A sociedade necessita de novos saberes e competências, 0 que incide no oferecimento de uma formação que contribua para que os licenciandos compreendam a complexidade das práticas que ocorrem nas escolas e "[...] que adquiram uma formação inicial que Ihes proporcione uma sólida base teórico-científica relativa ao seu campo de atuação e que a mesma seja desenvolvida e apoiada na reflexão e na investigação sobre a prática" (FIORENTINI, 2008, p. 49).

D'Ambrosio salienta que o ensino oferecido nas escolas precisa valorizar os aspectos conceituais dos conteúdos matemáticos, estimular a criatividade, a convivência produtiva e a consciência de cidadania, onde os professores atuem como comentaristas críticos e valorizem os aspectos culturais e sociais do cotidiano dos alunos (MACHADO; D'AMBROSIO; ARANTES, 2014). O autor acredita que na formação de professores de Matemática devem ser oferecidos espaços para reflexões críticas, propiciando meios para a inovação e para que possam ter "[...] a oportunidade de socialização de experiências e também para a geração de novos conhecimentos" (MACHADO; D'AMBROSIO; ARANTES, 2014, p. 160)

Mizukami (2008) menciona que na formação inicial de professores devem ser proporcionados meios para a ocorrência de processos formativos de ensino e aprendizagem da docência, que possibilitem aos futuros professores a obtenção de uma sólida formação teórico-prática e que os tornem aptos a atenderem às situações diversas no ensino. Para tanto, sugere a proposta de atividades que possibilitem trocas colaborativas, para que os futuros professores aprendam a investigar e a fundamentar as suas decisões nas práticas pedagógicas. Além disso, acredita que a reflexão deve ser um meio para que ocorra a superação de desafios e dilemas e para que adquiram maiores condições de se posicionar quanto às situações e aos momentos que são os mais adequados para serem desenvolvidos no cotidiano do trabalho docente.

Perez (2012) ressalta que a formação inicial de professores de Matemática precisa perpassar a trajetória pessoal e profissional dos futuros professores e contribuir para a incorporação da prática pela experiência docente. Essa incorporação pode ser potencializada por meio do processo de reflexão sobre a prática, pois "a reflexão é vista como um processo em que o professor analisa sua prática, compila dados, descreve situações, elabora teorias, implementa e avalia projetos e partilha suas ideias com colegas e alunos, estimulando discussões em grupo" (PEREZ, 2012, p. 274, grifo do autor), o que pode contribuir para aprendizagem e para implementação de novas perspectivas de ensino e aprendizagem.

De acordo com as concepções apresentadas, entende-se que a formação inicial de professores de Matemática é um período que precisa privilegiar o desenvolvimento de competências e habilidades profissionais, de modo que os futuros professores se tornem capazes de implementar inovações pedagógicas no exercício da profissão. Também, considera-se que a discussão, a investigação e a reflexão sobre as experiências docentes pode favorecer a cognição dos futuros professores de Matemática, visto que tais 
experiências propiciam a produção de conhecimentos, no que se refere a aspectos matemáticos, metodológicos, tecnológicos e relativos à abordagem de temas de relevância social.

\section{As perspectivas metodológicas da resolução de problemas, da utilização das tecnologias digitais e do design associadas por meio do design de problemas matemáticos}

Conforme as Diretrizes Curriculares Nacionais para os Cursos de Matemática, Bacharelado e Licenciatura (BRASIL, 2002, p. 3), há competências e habilidades que devem ser desenvolvidas por meio dos currículos dos Cursos, dentre elas: "[...] capacidade de compreender, criticar e utilizar novas idéias (sic) e tecnologias para a resolução de problemas; [...] habilidade de identificar, formular e resolver problemas na sua área de aplicação [...]". Essas competências e habilidades salientam que a resolução de problemas e a utilização das Tecnologias Digitais são perspectivas que, ao serem evidenciadas na formação inicial, podem contribuir para o processo formativo e educacional dos licenciandos em Matemática, tornando-os capacitados de exercer a profissão docente, apresentando competências para planejar atividades construtivas para os seus alunos.

Onuchic e Morais (2013) destacam que os licenciandos precisam ter a oportunidade de vivenciar diferentes abordagens metodológicas na sua formação como professor e utilizá-las com o propósito de lhes permitir examinar os conteúdos matemáticos com profundidade e refletir sobre esses, a fim de desenvolver a capacidade de atender às necessidades dos alunos da Educação Básica. Para as autoras, a resolução de problemas é uma abordagem que pode engajar os licenciandos no seu processo de formação, possibilitando-lhes o estabelecimento de relações entre os conceitos matemáticos, propiciando a incorporação da prática pelo exercício da profissão docente.

Conforme Ponte (2000), o uso das Tecnologias da Informação e Comunicação (TIC) e do ciberespaço na formação inicial de professores de Matemática pode contribuir para o desenvolvimento pessoal e oferecer possibilidades para as atividades cognitivas, afetivas e sociais dos alunos e dos professores, nos mais diferentes níveis e modalidades de ensino. Além disso, ressalta que a realização de projetos e de atividades exploratórias são abordagens formativas promissoras, que podem ser articuladas por meio da investigação e a reflexão sobre a prática docente.

Richit (2005) propõe que a formação do professor de Matemática seja um processo correlacionado que possibilite a aquisição de saberes vinculados às dimensões Matemática, Pedagógica e Tecnológica. Para que ocorra o desenvolvimento integral dos licenciandos, "[...] a ação docente, que tem como meta formar pessoas criativas, críticas e atuantes no seu contexto social, requer que sejam consideradas as características do 
meio, bem como as trajetórias cultural, histórica e étnica dos sujeitos [...]" (RICHIT, 2005, p. 161).

Mishra e Koehler (2006) são autores que, embora não se dediquem a realizar pesquisas na área da Educação Matemática, apresentam uma proposta de formação inicial de professores que visa contribuir para a construção do Conhecimento Tecnológico, Pedagógico e do Conteúdo (TPACK) ${ }^{2}$. Essa proposta pode possibilitar aos professores a aquisição de melhores condições de gerenciar a complexidade que as Tecnologias Digitais impõem ao ensino, bem como possam fazer o uso adequado de recursos tecnológicos no Design de experiências personalizadas, que visem à aprendizagem dos alunos (KOEHLER et al., 2013).

Koehler e Mishra (2005) destacam, também, que o Design possibilita o desenvolvimento do TPACK, já que pode contribuir para a aprendizagem por meio da experiência como designers. Essa atividade pode proporcionar a ocorrência de um ciclo de aprendizagem por meio do Design e/ou do re-design, em que a tomada de decisões e a busca de soluções possam incidir na prática docente e propiciar entendimentos pedagógicos.

Nesse sentido, entende-se que o Design é uma perspectiva metodológica que pode associar a resolução de problemas e a utilização das Tecnologias Digitais na formação inicial de professores de Matemática. Miskulin (2003) afirma que o Design de ambientes interativos para a aprendizagem colaborativa são cenários que podem possibilitar aos futuros professores a inserção no contexto de resolução de problemas como uma atividade de Design, onde possam aprender fazendo, de forma colaborativa, para serem construtores de sua formação, levando-os a refletir, de forma crítica e consciente, sobre o uso das tecnologias nas práticas pedagógicas.

Diante do exposto, salienta-se que a resolução de problemas, as Tecnologias Digitais e o Design podem ser associados por meio do Design de problemas com a utilização das Tecnologias Digitais. Acredita-se que essa perspectiva, quando evidenciada na formação inicial de professores de Matemática, pode ser um meio para que os futuros professores adquiriam a capacidade de escolher e de utilizar Tecnologias Digitais e para que compreendam a necessidade de produzir problemas abertos, que abordem temas de relevância social e que possibilitem, por meio do processo de resolução e solução, o emprego e a aprendizagem de novos conhecimentos matemáticos.

O Design de problemas com a utilização das Tecnologias Digitais, na concepção de Figueiredo e Dalla Vecchia (2015), tem, como propósito, a produção de problemas abertos com a utilização de Tecnologias Digitais, em que aspectos como a visualização, a experimentação, a investigação, dentre outros, sejam atribuídos. Tais problemas, ao serem produzidos por licenciandos e propostos em práticas pedagógicas, seja em disciplinas dos Cursos de Licenciatura em Matemática e/ou em turmas de alunos de Educação Básica, podem contribuir para a discussão, a investigação e a reflexão sobre essas experiências e possibilitar a constatação das potencialidades e/ou limitações que

\footnotetext{
2"Technological Pedagogical Content Knowledge".
} 
essa perspectiva metodológica pode proporcionar ao processo de ensino e aprendizagem da Matemática (FIGUEIREDO, 2017).

Essa perspectiva metodológica também pode contribuir para o ensino e aprendizagem da Matemática através da resolução de problemas. Nessa abordagem, de acordo com Onuchic e Allevato (2011, p. 79), "[...] o problema é visto como ponto de partida para a construção de novos conceitos e novos conteúdos; os alunos sendo coconstrutores de seu próprio conhecimento e, os professores, os responsáveis por conduzir esse processo".

Conforme Pozo (1998), a Educação Matemática precisa oportunizar meios para que os alunos aprendam conhecimentos e desenvolvam habilidades que os tornem capazes de resolver problemas, em diferentes contextos. Para isso, acredita que "[...] os alunos que hoje aprenderem a aprender estarão, [...] em melhores condições de adaptarse às mudanças culturais, tecnológicas e profissionais que nos aguardam" (POZO, 1998, p. 9).

Pais (2013) afirma que a sociedade da informação costuma valorizar a competência de resolver problemas, o que, a seu ver, pode ser desenvolvido com a utilização dos recursos oferecidos pela Informática, já que esses recursos favorecem o trabalho em equipe e a obtenção rápida de informações. Além disso, aponta que outras competências e habilidades podem ser desenvolvidas por através da resolução de problemas com o uso de tecnologias, sendo elas: utilizar diversificadas formas de linguagem; argumentar oralmente; comunicar ideias objetivas; articular ideias e ações; obter soluções criativas para problemas; construir conceitos; etc.

O NCTM $^{3}$ (2014) sugere, dentre os princípios e ações norteadores, que computadores, telefones, calculadoras, softwares, jogos, dentre outros recursos, sejam utilizados no desenvolvimento de habilidades de resolução de problemas, para a exploração de ideias e para uma aprendizagem significativa dos conceitos matemáticos. Também, nesses princípios e ações, são apontados que as tecnologias podem possibilitar a resolução de problemas mais complexos, evidenciando, assim, um raciocínio mais formal.

Allevato (2005) aponta que a escolha e/ou a elaboração de problemas por parte do professor requer a consideração dos conteúdos e dos conceitos matemáticos que, com o uso de Tecnologias Informáticas, possam ser trabalhados. Para a autora, mesmo nos problemas fechados, o uso das tecnologias pode possibilitar novos processos de resolução, em um trabalho mais colaborativo, incentivando a investigação, a discussão e a troca de ideias. Em relação aos problemas abertos, "[...] em virtude da imprevisibilidade presente nas atividades realizadas com o computador, novos e inesperados problemas, na maior parte das vezes, propostos pelos próprios alunos, podem surgir" (ALLEVATO, 2005, p. 99).

Para que a resolução de problemas associada ao uso das Tecnologias Digitais contribua para a produção de conhecimentos matemáticos e tecnológicos, acredita-se que

\footnotetext{
3"National Council of Teachers of Mathematics".
} 
são necessárias a atribuição de aspectos, tais como: a visualização, a experimentação, a investigação, a experiência estética, dentre outros. Nesse viés, destacam-se Borba, Silva e Gadanidis (2014), que salientam que a visualização é um processo que oferece meios para a exploração de conexões entre representações e a experimentação pode propiciar a ocorrência de cenários de ensino e de aprendizagem. Além disso, mencionam que a exploração na resolução de problemas matemáticos pode proporcionar meios para a "[...] investigação Matemática, ou seja, um ambiente [...] de formulação de conjecturas acerca de um problema e busca por possíveis e diversificadas soluções" (BORBA; SILVA; GADANIDIS, 2014, p. 50).

Rosa (2015, p. 80) destaca que a experiência estética é outro aspecto que pode permitir a vivência de informações "[...] a partir do movimento, da cor, da imagem e todas as relações e/ou links que se façam com esses aspectos para que se produza conhecimento e, em específico, conhecimento matemático". Desse modo, as práticas educativas que visam proporcionar a experiência estética ou que consideram os aspectos estéticos como meios para instigar a realização de atividades, podem favorecer 0 processo de reflexão sobre as mesmas, o que contribui para a produção de conhecimentos matemáticos associados ao uso de recursos tecnológicos.

A resolução de problemas com a utilização de Tecnologias Digitais também se apresenta em alguns tipos de Design instrucional${ }^{4}$. Como exemplo, cita-se o Design de ambientes de aprendizagem interativos que, de acordo com Jonassen (2003), são ambientes desenvolvidos para que os futuros profissionais tenham a oportunidade de solucionar problemas que sejam semelhantes aos que pode encontrar no exercício da profissão.

Jonassen (2011) também ressalta que as atividades que propõem a resolução de problemas como um processo de Design são meios para tornar o processo de resolução mais complexo, pois o aluno tem a oportunidade de tomar decisões e de utilizar as suas próprias habilidades. Nesse intuito, o professor precisa propor uma atividade em que 0 aluno é quem delimita o problema a ser resolvido e as metas que serão atingidas, assim como o resultado a ser obtido necessita refletir as suas decisões.

Dessa forma, um dos tipos de Design que mais se aproxima das concepções explicitadas é o Design de problemas com a utilização das Tecnologias Digitais. Esse Design oportuniza a problematização, ou seja, outros problemas podem ser determinados na tentativa de obter a(s) solução(ões) do problema proposto inicialmente (FIGUEIREDO; DALLA VECCHIA, 2015). Nesse Design, além de serem atribuídos aspectos, podem ser considerados os interesses e o desenvolvimento cognitivo dos alunos, valorizando-se 0 trabalho colaborativo entre os alunos e o professor.

\footnotetext{
${ }^{4}$ Para Filatro (2008, p. 3), é uma "[...] ação intencional e sistemática de ensino que envolve o planejamento, o desenvolvimento e a aplicação de [...] atividades [...] em situações didáticas específicas, a fim de promover [...] a aprendizagem [...]".
} 


\section{Procedimentos metodológicos}

O presente estudo tem por objetivo investigar quais aspectos matemáticos, metodológicos, tecnológicos e relativos à abordagem de temas de relevância social que se apresentam na formação inicial de professores de Matemática, quando licenciandos realizam Design de problemas com a utilização das Tecnologias Digitais. Para atingi-lo, optou-se por realizar o Curso de Extensão Design de problemas com a utilização das Tecnologias Digitais na Educação Matemática, em que o público-alvo eram licenciandos de Cursos de Licenciatura em Matemática.

Esse Curso foi promovido na modalidade presencial, com o apoio do Programa de Pós-Graduação em Ensino de Ciências e Matemática (PPGECIM) e da Coordenadoria de Extensão da Pró-Reitoria de Extensão e Assuntos Comunitários da Universidade Luterana do Brasil (ULBRA), campus Canoas-RS. O Curso teve 40 horas de duração, que foram distribuídas em 12 encontros (5 não presenciais, extraclasse, e 7 presenciais).

Nessa proposta de formação, foram planejadas atividades com a intencionalidade de promover um ambiente/cenário para a produção de conhecimentos matemáticos, metodológicos, tecnológicos e sobre a abordagem de temas de relevância social. Para tanto, os licenciandos tiveram a oportunidade de vivenciar experiências que permitiram discussões, investigações e reflexões relativas à resolução e ao Design de problemas com a utilização das Tecnologias Digitais na Educação Matemática.

O paradigma metodológico adotado na investigação foi a abordagem qualitativa, com características do método de estudo de caso. De acordo com Goldenberg (2004), o estudo de caso permite a reunião e a descrição de informações detalhadas, com o propósito de compreender uma determinada situação ou realidade social e os sujeitos pesquisados em seus próprios termos, contribuindo para a compreensão das particularidades de uma situação, conforme o significado que é atribuído pelos mesmos, o que, nesta investigação, contribuiu para a coleta, descrição e análise dos dados.

Os instrumentos utilizados para coletar os dados foram: observações participantes; entrevistas; gravações de áudio e vídeo com o uso do software Screencast-O-Matic, no decorrer das atividades propostas e realizadas nos encontros presenciais; e gravações de áudio realizadas com 0 uso de um smartphone, nas entrevistas abertas e não estruturadas realizadas pela pesquisadora com cada um dos grupos de licenciandos e no último encontro do Curso. Além disso, utilizou-se o Ambiente Virtual de Aprendizagem Moodle (http://matematica.ulbra.br/moodle), para propor as atividades e para que os licenciandos registrassem os dados solicitados.

No decorrer do Curso foram produzidos quatro problemas matemáticos pelos licenciandos, mas, neste artigo, optou-se por apresentar apenas um dos problemas que foram produzidos no decorrer do processo formativo, no caso o problema Rio de Janeiro: viajando na Matemática. Esse problema foi produzido pela dupla de licenciandos A e $\mathrm{B}^{5}$, alunos do Curso de Licenciatura em Matemática da Universidade de Santa Cruz do Sul

\footnotetext{
${ }^{5}$ Para preservar a identidade dos licenciandos que participaram da investigação, foram utilizadas letras maiúsculas do alfabeto para denominá-los.
} 
(UNISC), campus Santa Cruz do Sul-RS. Na próxima seção apresentam-se os principais resultados, que foram obtidos nos últimos quatro encontros presenciais do Curso.

\section{Os resultados obtidos com a produção e resolução do problema}

Os licenciandos A e B realizaram o Design do problema Rio de Janeiro: viajando na Matemática, com o objetivo de que esse problema fosse proposto e resolvido por alunos dos Anos Finais do Ensino Fundamental. Para atingir o objetivo, foram propostas e realizadas atividades, que se constituíram como etapas no Design do problema.

No quarto encontro presencial, com duração de 4 horas, foi proposto aos licenciandos o Design de um problema aberto com o uso de Tecnologias Digitais e que aspectos como a visualização, a investigação, a experimentação, etc., fossem atribuídos. Nas gravações de áudio e vídeo realizadas com o uso do software Screencast-O-Matic, constatou-se que os licenciandos A e B escolheram como temática social o planejamento de uma viagem, de Las Vegas-USA ao Rio de Janeiro-BR, que o personagem Pedro deveria realizar.

Primeiramente, os licenciandos elaboraram o folder de propaganda dessa viagem, que seria entregue na forma impressa para cada um dos alunos no momento da resolução do problema. A elaboração desse folder ocorreu no aplicativo Paint, que é um acessório do Sistema Operacional Windows, e utilizaram imagens disponíveis em sites. Nele escreveram as despesas que o personagem Pedro teria na viagem, que foram determinadas de acordo com as pesquisas que realizaram na Internet.

Nos registros das observações da pesquisadora, constatou-se que os licenciandos A e B tiveram a preocupação de escrever no enunciado do problema informações que tivessem coerência com as que os resolvedores poderiam encontrar na Internet. Optaram por elaborar uma imagem com o uso do Paint, que foi obtida no site Google Maps (https://maps.google.com.br), pois essa apresentava o trajeto e o tempo de duração da viagem, de Las Vegas-USA ao Rio de Janeiro-BR.

Nas gravações realizadas com o uso do software Screencast-O-Matic, pode-se verificar que os licenciandos $\mathrm{A}$ e $\mathrm{B}$ optaram por relatar o modo como foi realizado 0 Design do problema, como se observa no recorte do diálogo a seguir:

B: A gente criou esse problema que vai ter várias etapas, onde os alunos vão ter que ir construindo toda resolução, administrar o dinheiro do Pedro.

A: Então primeiro poderão ver quanto custou essas passagens, por isso que a gente deu essa função, para eles descobrirem o valor da passagem de ida e consequentemente da volta também, fazendo multiplicado por dois [...] o valor das passagens, para depois diminuírem do dinheiro que Pedro tem e transformarem esses dólares em reais.

B: [...] E logo após eles vão ter que administrar esses gastos dele no Brasil.

A: [...] $E$ a gente fez junto ao folder, o [licenciando] $B$ até colocou os gastos organizados, para que eles tenham um caminho [...], o que ele vai gastar. 
B: Então a gente estipulou alguns gastos que ele terá [...]. A gente usou o PowerPoint para fazer o problema [...].

Conforme o diálogo, entende-se que houve a pretensão de trabalhar os conteúdos de Matemática Financeira, como Valores Monetários e a Conversão de moedas (de dólares para reais), utilizando as Quatro Operações envolvendo Números Racionais Decimais e o modelo matemático que representava uma Função Linear. Também, os licenciandos A e B utilizaram um documento de PowerPoint para apresentar o problema.

O resultado final, ou seja, o problema produzido pode ser observado na Figura 1.

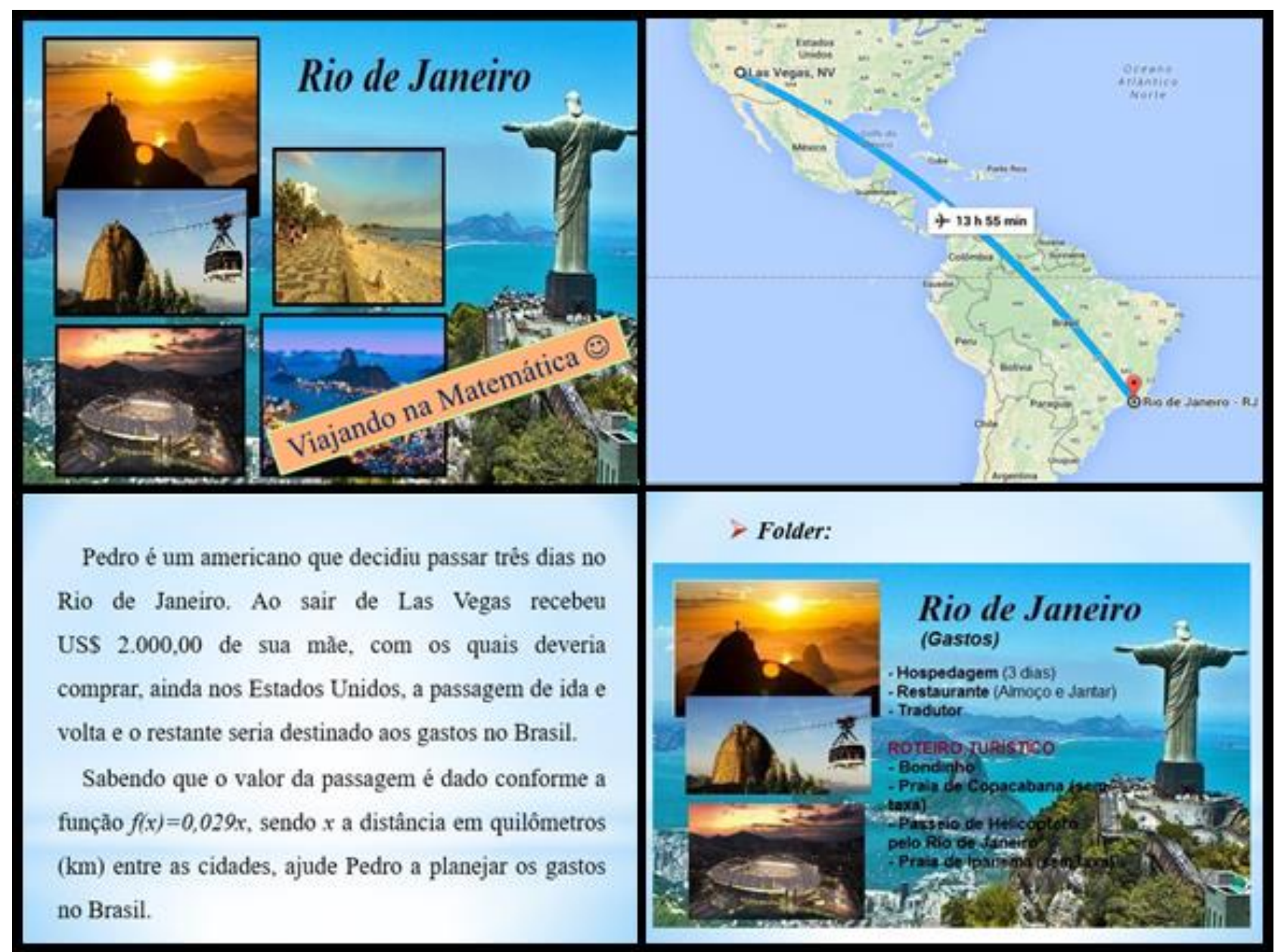

Figura 1 - Problema Rio de Janeiro: Viajando na Matemática.

Como se observa, no primeiro slide, os licenciandos colocaram uma imagem igual

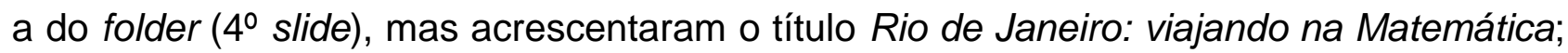
no segundo slide, colocaram a imagem que elaboraram, com o tempo de duração da viagem, visando contribuir com o processo de resolução do problema; no terceiro slide, escreveram o enunciado do problema, apresentando informações relevantes aos resolvedores (o valor máximo a ser gasto por Pedro na viagem, o destino da viagem e 0 modelo matemático que permitiria a obtenção do valor da passagem em reais), e, no quarto e último slide, apresentaram o folder que seria entregue na forma impressa para os resolvedores.

O problema produzido permite a constatação de que os licenciandos $A$ e $B$ atribuíram os seguintes aspectos: as características de um problema aberto, visto que a 
resolução do problema pode admitir a obtenção de diferentes soluções (ALLEVATO, 2005); a exploração de diferentes formas de resolução, a investigação de informações com o uso da Internet e a visualização, pois a imagem com o mapa favorece o processo de resolução (BORBA; SILVA; GADANIDIS, 2014); e aspectos estéticos (ROSA, 2015), por meio das imagens utilizadas e daquelas que seriam apresentadas nos sites pesquisados (as imagens das opções de alimentação e dos passeios mencionados no folder).

No quinto encontro presencial, que teve duração de 4 horas, o problema foi resolvido por outro grupo (licenciandas $\mathrm{C}, \mathrm{E}$ e K), alunas do Curso de Matemática da ULBRA, campus Canoas/RS. Observou-se que essas licenciandas investigaram, em sites disponíveis na Internet, informações sobre os melhores preços dos gastos que eram mencionados no folder e que o personagem Pedro poderia ter na viagem.

No Fórum Troca de ideias sobre o Design e a resolução dos problemas e de sugestões para um possível re-design, que foi proposto na Plataforma Moodle, as licenciandas $\mathrm{C}, \mathrm{E}$ e $\mathrm{K}$ fizeram comentários e/ou sugestões relativos ao enunciado do problema, bem como a pesquisadora os complementou, como pode ser verificado na Figura 2.

\begin{tabular}{|c|l|}
\hline PARTICIPAÇÃO & \multicolumn{1}{c|}{ COMENTÁRIOS E SUGESTÕES } \\
\hline Licenciandas C, E e K & $\begin{array}{l}\text { No enunciado deveria estar estipulado a moeda da passagem. } \\
\text { As letras no folder deveriam estar mais visíveis. } \\
\text { Mostrar como que surgiu a função do valor da passagem, pois surgiu dúvidas } \\
\text { sobre o modelo da função. }\end{array}$ \\
\hline Pesquisadora & $\begin{array}{l}\text { Para complementar, no problema produzido pelo B e pela A há a sugestão de } \\
\text { contratação de um tradutor, mas observei no processo de resolução que as } \\
\text { licenciandas C, E e K apresentaram dificuldades em encontrar na Web uma } \\
\text { possibilidade, de acordo com o que foi solicitado. Essa sugestão de contratação } \\
\text { poderia não ser necessária, se imaginássemos que o americano tivesse } \\
\text { aprendido a Língua Portuguesa antes da viagem. }\end{array}$ \\
\hline Licencianda A & $\begin{array}{l}\text { Para estabelecermos a função que está [...] [no] problema, procuramos o valor } \\
\text { da passagem de ida, em dólares, e depois de termos encontrado a distância } \\
\text { entre Las Vegas e Rio de Janeiro, dividimos essas duas informações. Ou seja, o } \\
\text { valor da passagem dividido pela distância entre [...][as cidades] para que, desse } \\
\text { modo, quando multiplicado esse resultado (0,029) pela distância (que os alunos } \\
\text { tiveram que procurar) fosse obtido o preço da passagem em dólares. É como se } \\
\text { tivéssemos feito uma ponte para [...] encontrar o valor da passagem. }\end{array}$ \\
\hline
\end{tabular}

Figura 2 - Participações no Fórum Troca de ideias sobre o Design e a resolução dos problemas e de sugestões para um possivel re-design.

Pelas participações, identificou-se que as licenciandas C, E e K fizeram sugestões, como escrever o tipo de moeda (dólares) fornecido e o valor da passagem e fazer alterações nas cores do folder. Entretanto, a principal dúvida delas era como os licenciandos A e B haviam obtido a Função apresentada no enunciado. Houve, inclusive, a sugestão por parte das licenciandas $\mathrm{C}, \mathrm{E}$ e $\mathrm{K}$ de que a origem da Função fosse apresentada no próprio enunciado do problema e os licenciandos A e B explicassem como a obtiveram, destacando que o objetivo da mesma era ajudar no processo de resolução do problema, como um procedimento.

No Fórum, a licencianda $A$ explicou como foi elaborado o modelo matemático apresentado no enunciado do problema, o que possibilita o entendimento de que esse modelo foi a maneira encontrada pelos licenciandos A e B para favorecer a resolução do 
problema, pois, ao pesquisarem o valor a ser pago pela passagem de ida, os resolvedores iriam encontrar dificuldades em pesquisar em sites escritos em Língua Inglesa. Contudo, a pesquisadora aproveitou o Fórum para fazer um comentário relativo à determinação da contratação de um tradutor e para que os licenciandos $A$ e $B$ repensassem sobre essa opção apresentada no folder.

No sexto encontro presencial, com duração de 4 horas, foi proposto a realização de modificações ou o re-design do problema, com base nos comentários e sugestões que foram escritos no Fórum. Os licenciandos $A$ e $B$ discutiram e tomaram a decisão de não realizar alterações no problema que produziram.

Também, nesse encontro, foi proposto o planejamento da prática pedagógica em que o problema seria resolvido por alunos da Educação Básica. Na Figura 3 pode ser verificado o planejamento realizado pelos licenciandos $A$ e $B$.

\section{Professores: A e B.}

\section{PLANEJAMENTO DA PRÁTICA PEDAGÓGICA}

Escola: uma Escola Municipal de Ensino Fundamental, localizada na zona urbana do município de Santa Cruz do Sul-RS.

Carga horária: 4 horas-aula.

Número de alunos e o ano de ensino: 18 alunos de um 9a ano do Ensino Fundamental.

Recursos: quadro branco e pincel; folder impresso; computadores com acesso à Internet e multimídia.

Objetivos: utilizar o conceito de Função em uma situação-problema que envolve o uso das Tecnologias Digitais; empregar conhecimentos matemáticos e tecnológicos durante o processo de resolução; interrelacionar a Matemática à situações semelhantes às que podem ocorrer no cotidiano.

\section{Procedimentos:}

As atividades serão realizadas em dois dias distintos, devido à carga horária disponibilizada pela Escola. No primeiro dia, a aula será iniciada com a apresentação do problema e serão dadas orientações sobre sua solução e procedimentos que deverão ser adotados para disponibilizar as respostas. $\mathrm{Na}$ sequência, será solicitado aos alunos que iniciem o processo de resolução e, caso surjam dúvidas, essas serão esclarecidas pelos professores. No segundo dia será concluído a resolução do problema proposto. A solução do problema será apresentada em documento do Google Docs.

Figura 3 - Planejamento da prática pedagógica elaborado pelos licenciandos A e B.

De acordo com o planejamento, os licenciandos $A$ e $B$ escolheram uma turma composta por 18 alunos de um $9^{\circ}$ ano do Ensino Fundamental para aplicação do problema. Nos objetivos, mencionaram o uso dos conhecimentos prévios necessários, destacando que o problema se tratava de uma situação que, para ser resolvida, necessitaria do uso de conhecimentos matemáticos e tecnológicos, embora não especificassem os conteúdos matemáticos que seriam trabalhados. Em relação aos procedimentos, destacam-se a organização da prática e as ações que seriam realizadas conforme a carga horária disponibilizada pela Escola.

Nos registros das observações da pesquisadora, verificou-se outras informações sobre a prática pedagógica. Os licenciandos disseram para a pesquisadora que os alunos do $9^{\circ}$ ano iriam resolvê-lo em duplas e que as resoluções e soluções do problema seriam escritas em documentos do Google Docs (https://docs.google.com/document/u/0/).

No sétimo e último encontro presencial do Curso de Extensão, com duração de 4 horas, a pesquisadora realizou uma entrevista aberta e não estruturada com os licenciandos $A$ e $B$, com a pretensão de obter informações relevantes quanto a prática pedagógica que realizaram e para que ocorressem discussões, investigações e reflexões sobre a mesma. No primeiro questionamento da entrevista foi solicitado o relato de como 
ocorreu a prática pedagógica, em especial, dos aspectos relacionados ao seu desempenho como docentes. O recorte do diálogo pode ser constatado na transcrição:

Pesquisadora: Gostaria que vocês relatassem como ocorreu a prática pedagógica. [...] Ela contribuiu para a formação de vocês?

A: A gente chegou lá e era tudo meio novo. Eu conhecia a Escola, o B conhecia também, mas os alunos a gente não conhecia [...]. A gente estava bem nervoso, [...], não sabia como começar, o que falar.

Pesquisadora: O professor titular [da turma] estava junto?

B: Como era no primeiro dia e na aula de Informática, o professor acompanhou, a gente se sentiu, pelo menos eu, meio pressionado e ele, às vezes, até interferiu em algumas coisas, ele perguntou para os alunos coisas que a gente deveria perguntar [...]. No segundo foi bem mais tranquilo, porque tinham só quatro alunos, dos quatro, dois formavam uma dupla da aula anterior, e os outros dois estavam sozinhos, porque a dupla não havia vindo. Foi bem rápido, porque [...] aqueles que tinham vindo naquele dia já tinham dado um grande andamento no problema e eles só finalizaram [...].

Conforme o diálogo, os licenciandos A e B apresentaram dificuldades iniciais para realizar a prática pedagógica, pois não conheciam os alunos do $9^{\circ}$ ano e a interferência do professor titular da turma os deixou inseguros, o que dificultou a interação entre os licenciandos e os alunos. Mas, no segundo dia, que deram continuidade à resolução do problema, eles se sentiram mais seguros para orientá-los, já que o professor titular não estava presente e compareceram apenas 4 alunos. Dessa forma, considera-se que a prática pedagógica deveria ter sido realizada com uma maior carga horária, para que todos os alunos da turma tivessem a oportunidade de solucionar o problema, embora que, para os licenciandos, a redução do número de alunos tenha sido algo positivo.

$O$ segundo e terceiro questionamentos tinham como finalidades que os licenciandos $A$ e $B$ citassem os conhecimentos matemáticos trabalhados através da resolução do problema e as estratégias utilizadas e/ou elaboradas pelos alunos. $O$ recorte do diálogo pode ser verificado a seguir.

Pesquisadora: [...] Em relação aos conhecimentos matemáticos, [...] conseguiram trabalhar o que queriam?

B: Quando a gente trabalhou com o problema eles já tinham começado a trabalhar com Funções e acho que algumas coisas eles não tinham esclarecido totalmente, sobre o conceito de função, que tem que colocar o valor no lugar do x para poder descobrir o valor do y; a gente teve que explicar que deveriam descobrir a distância em quilômetros para poder multiplicar, porque eles não raciocinaram que, a partir daí, é que iriam descobrir o valor da passagem.

A: É, a gente começou, explicou, [...] porque eles não sabiam como começar [...]!

Pesquisadora: Vocês acham que eles tinham ou não alguma experiência em resolver problemas? 
A: Para alunos é muito difícil, porque o problema era contextualizado [...], quando tem todo um "problema" é bem mais difícil, pois até saber o que fazer, a gente viu como isso é trabalhoso!

Pesquisadora: E eles criaram estratégias [...]?

B: Como a gente percebeu que eles não estavam conseguindo elaborar o roteiro para resolver o problema, passamos alguns tópicos e a partir desses tópicos que eles completavam e resolviam o problema.

A: Até teve uma menina que, [...] para achar o valor do tradutor, tivemos que ajudála.

No diálogo, nota-se que os licenciandos $A$ e $B$ reconheceram que os alunos ainda não haviam aprendido os conhecimentos que eram necessários para resolver o problema, o que os levou a ensiná-los através da resolução do problema. Essa decisão veio ao encontro do que ressaltam Onuchic e Allevato (2011), em relação à necessidade de envolver os alunos através da resolução de problemas e que o professor acompanhe o processo, para que possam aprender novos conhecimentos matemáticos através da resolução do problema.

Além disso, nesse diálogo, os licenciandos A e B destacaram que os alunos tiveram dificuldades na interpretação do problema e que, por abordar um tema de relevância social, isso tornou-o complexo. Para que resolvessem o problema, os licenciandos precisaram orientá-los, propondo, inclusive, alguns tópicos para serem (re)pensados e utilizados como estratégias de resolução.

O quarto questionamento teve como objetivo obter informações relativas às Tecnologias Digitais utilizadas no Design do problema e sobre o tipo de problema produzido e proposto, para que expusessem os conhecimentos metodológicos que entendiam como desenvolvidos por eles. A transcrição desse diálogo consta a seguir.

Pesquisadora: Em relação às tecnologias que vocês utilizaram no Design do problema, vocês acham que elas contribuíram?

B: A gente pôde perceber que era algo muito novo para eles, geralmente eles estão acostumados somente com quadro, sala de aula e problemas que não têm contextualização nenhuma e quando eles ficam de frente com um problema assim, que podem utilizar a Internet para resolver, acho que isso acaba sendo mais prazeroso [...] e é uma novidade [...], porque eles não estão acostumados com esse tipo de atividade.

Pesquisadora: E vocês, [...] como futuros professores, qual a sua opinião sobre esse tipo de problema?

A: Teve uma hora que uma menina disse, a gente não perguntou e ela espontaneamente falou que no início ela não estava gostando, não sabia o que fazer, estava meio perdida, mas depois foram gostando, viram os resultados.

Pesquisadora: Porque eles se envolveram e as respostas eram criações deles. Vocês deram um caminho que não era o que levaria ao resultado final. [...] Eles tiveram que pensar na situação [...]. 
B: [...] Eles conseguiram entender que a Matemática não é só algo abstrato [...], que ela está presente no nosso dia a dia, em situações que nós nem percebemos.

Pesquisadora: Em relação a sua formação, quanto aos conhecimentos metodológicos, [...] vocês consideram que esse tipo de problema é válido?

B: Com certeza, porque isso instiga o aluno a buscar uma solução para o problema, porque simplesmente ele não vai encontrar o resultado e acabou, ele vai se envolver com o problema para buscar a solução.

A: Eu acredito que não vai ser em todas as aulas que terá uma proposta assim diferente, algo atrativo, eu achei muito válido. Às vezes eu e o [licenciando] $B$ conversamos, a gente gosta muito de quadro, do papel e de estar fazendo cálculos, mas a gente aprendeu assim.

B: Só que se a gente gostou de aprender assim desse jeito, outros não gostaram, e por isso a Matemática é vista com maus olhos, porque a maioria dos alunos não veem aplicação dela na realidade, pra que aprender então!

Pesquisador: [...] A escola deveria preparar para resolver problemas, em todas as disciplinas, problemas que fossem semelhantes aos que ocorrem no dia a dia [...] do aluno, só que isso não acontece [...]. Não são proporcionados meios para pensar sobre as coisas, como as situações ocorrem e que a Matemática seja utilizada [...].

De acordo com o diálogo, os licenciandos A e B consideram que a resolução do problema foi uma atividade diferenciada para os alunos, visto que a Internet foi utilizada como um recurso no processo de resolução. Novamente, os licenciandos ressaltaram que, por ser contextualizado, o problema contribuiu para que os alunos do 9o ano empregassem e reconhecessem a aplicabilidade dos conhecimentos matemáticos utilizados e aprendidos através da resolução e solução do problema. Para os licenciandos, problemas como o que produziram podem proporcionar aos alunos uma experiência inovadora e atrativa no ensino da Matemática.

Conforme as discussões e reflexões ocorridas por meio da entrevista aberta e não estruturada, foi possível compreender que as experiências de designer de problemas e de docente contribuíram para que os licenciandos A e B pudessem se conhecer e refletir sobre as suas ações e dos alunos do $9^{\circ}$ ano na prática pedagógica, o que contribuiu para que tais licenciandos produzissem conhecimento-na-ação (SCHÖN, 2000), em todos os aspectos referidos (matemático, metodológicos, tecnológico e relativos à abordagem de temas de relevância social). Segundo as respostas dos licenciandos para os questionamentos da entrevista, a dimensão social perpassou as demais dimensões, já que reconheceram que o problema produzido contribuiu com o processo formativo dos alunos do $9^{\circ}$ ano do Ensino Fundamental, tanto no aspecto matemático como tecnológico.

A proposta de formação inicial implementada por meio do Curso de Extensão veio ao encontro do modelo de formação denominado por Shulman (2014) como processo de raciocínio pedagógico. O tema de relevância social abordado, os conteúdos matemáticos e as Tecnologias Digitais utilizadas foram transformadas por meio da produção do problema, bem como a resolução do mesmo possibilitou aos licenciandos a avaliação do 
entendimento dos alunos do $9^{\circ}$ ano e, por sua vez, a investigação e a reflexão sobre os resultados obtidos com a realização da prática pedagógica.

\section{Considerações finais}

Com os resultados obtidos com a realização da investigação, foi possível depreender que o Design de problemas abertos com a utilização de Tecnologias Digitais pode potencializar a produção de conhecimentos e contribuir para o desenvolvimento de competências e habilidades que são necessárias no desempenho da profissão docente. $A$ própria atividade de Design de um problema do tipo aberto e contextualizado pode ser considerada como uma situação problemática a ser solucionada pelos licenciandos, pois, de forma colaborativa, precisam produzir um problema matemático que atenda a objetivos de ensino e aprendizagem e refletir sobre as suas decisões e acerca dos resultados obtidos com a resolução do problema, ao mesmo tempo que tais ações têm como propósito contribuir com a sua formação profissional (JONASSEN, 2003, 2011).

No processo formativo dos licenciandos $A$ e $B$, verificou-se que produziram conhecimentos matemáticos, sobre como evidenciar o uso de conhecimentos prévios e ensinar novos conhecimentos matemáticos através da resolução do problema; metodológicos, ao realizarem etapas no processo de Design, ao planejarem e realizarem a prática pedagógica em que o problema seria proposto e ao constatarem a necessidade de ensinar conhecimentos sobre Funções no decorrer da resolução do problema; tecnológicos, ao escolherem Tecnologias Digitais tanto para serem utilizadas no Design como para serem usadas pelos alunos do 9a ano na resolução e solução do problema; e relativos à abordagem de temas de relevância social, pois escolheram um tema que contribuiu para que os alunos aprendessem a planejar os gastos de uma viagem. Desse modo, o processo formativo desses licenciandos apresentou indícios de que produziram conhecimentos de forma correlacionada, ou seja, o Design de problemas com a utilização das Tecnologias Digitais veio ao encontro das concepções de formação de professores que são defendidas por Koehler et al. (2013), Mishra e Koehler (2006) e Richit (2005).

Dentre os resultados obtidos, identificou-se, também, que os licenciandos A e B produziram o problema de modo que contribuísse para que os alunos utilizassem conhecimentos sobre Valores Monetários, Conversão de moedas (de valores em dólares para reais), Quatro Operações com Números Racionais Decimais e Funções. No entanto, os licenciandos constataram lacunas na aprendizagem dos alunos, principalmente relacionadas ao uso do modelo que representava uma Função Linear, o que os levou a tomarem a iniciativa de ensiná-los e auxiliá-los no processo de resolução. Apesar disso, entende-se que o tema abordado contribuiu para a contextualização do problema e para que os conhecimentos matemáticos escolhidos pudessem ser utilizados e outros fossem aprendidos pelos alunos do 9ำ ano.

Em relação aos recursos tecnológicos, constatou-se que esses licenciandos utilizaram recursos no Design do problema que já eram conhecidos por eles (documento de PowerPoint, o aplicativo Paint e a Internet), assim como o que sugeriram para os alunos apresentarem a resolução do problema (Google Docs). Embora que não tenham 
aprendido a utilizar novos recursos tecnológicos, considera-se que os resultados obtidos foram significativos para os licenciandos $\mathrm{A}$ e B, por terem tido a oportunidade de vivenciar experiências diferenciadas e exploratórias (PONTE, 2000), que thes permitiram associar mais de uma perspectiva metodológica (ONUCHIC; MORAIS, 2013).

No que se refere as competências e habilidades desenvolvidas e/ou que se apresentaram no decorrer do processo formativos, considera-se que os licenciandos $\mathrm{A} e$ B apresentaram as capacidades de: tomar decisões no Design do problema, no planejamento e no decorrer da prática pedagógica; escolher um tema de relevância social que poderia favorecer a aprendizagem de como planejar os gastos de uma viagem; escolher conteúdos matemáticos para serem trabalhados através da resolução do problema; planejar e realizar a prática pedagógica, buscando atingir os objetivos de ensino e aprendizagem. Entende-se que tais competências e habilidades se aproximaram das que são mencionadas nas Diretrizes Curriculares Nacionais para os Cursos de Matemática, Bacharelado e Licenciatura (BRASIL, 2002).

Os resultados obtidos com o Design do problema e a realização da prática pedagógica também favoreceram a troca de ideias entre os licenciandos $A$ e $B$, as licenciandas $\mathrm{C}, \mathrm{E}$ e $\mathrm{K}$ e a pesquisadora, assim como a discussão, a investigação e a reflexão sobre tais práticas, entre os licenciandos $\mathrm{A}$ e $\mathrm{B}$ e a pesquisadora, por meio da entrevista aberta e não estruturada. Com isso, os licenciandos A e B puderam (re)construir suas concepções quanto à resolução de problemas, o uso de Tecnologias Digitais e do Design no processo de ensino e aprendizagem, apontando, inclusive, possibilidades que podem emergir através da produção de problemas abertos e contextualizados com a utilização das Tecnologias Digitais na Educação Matemática.

\section{Referências}

ALLEVATO, N. S. G. Associando o computador à resolução de problemas fechados: análise de uma experiência. 2005. 378f. Tese (Doutorado em Educação Matemática) Instituto de Geociências e Ciências Exatas, Universidade Estadual Paulista Júlio de Mesquita Filho, Rio Claro, 2005.

AMBIENTE VIRTUAL DE APRENDIZAGEM MOODLE. Ambiente virtual do Curso de Extensão Design de problemas com a utilização das Tecnologias Digitais na Educação Matemática. Disponível em: <http://matematica.ulbra.br/moodle>. Acesso em: 10 nov. 2016.

BORBA, M. C.; SILVA, R. S. R. da; GADANIDIS, G. Fases das tecnologias digitais em Educação Matemática: sala de aula e internet em movimento. 1. ed. Belo Horizonte: Autêntica, 2014. 149 p. (Coleção Tendências em Educação Matemática).

BRASIL. Parecer CNE/CES no 1.302, de 6 de outubro de 2001. Aprova as Diretrizes Curriculares Nacionais para os Cursos de Matemática, Bacharelado e Licenciatura. Diário Oficial [da] República Federativa do Brasil, Brasília, DF, 5 mar. 2002. Seção 1, p. 15.

FIGUEIREDO, F. F. Design de problemas com a utilização das Tecnologias Digitais na formação inicial de professores de Matemática. 2017. 275f. Tese (Doutorado em Ensino de Ciências e Matemática) - Programa de Pós-graduação em Ensino de Ciências e Matemática, Universidade Luterana do Brasil, Canoas, 2017. 
FIGUEIREDO, F. F.; DALLA VECCHIA, R. O design de problemas com as tecnologias digitais no ensino da Matemática. In: CONFERENCIA INTERAMERICANA DE EDUCACIÓN MATEMÁTICA, 14., 2015b, Chiapas. Anais eletrônicos... Chiapas: XIV CIAEM, 2015. Disponível em: <file://C:/Users/Fabiane/Downloads/1298-3628-1-PB\%20(2).pdf>. Acesso em: 10 jul. 2015.

FIORENTINI, D. A Pesquisa e as Práticas de Formação de Professores de Matemática em face das Políticas Públicas no Brasil. Bolema, Rio Claro, v. 21, n. 29, p. 43-70, fev. 2008.

GOLDENBERG, M. A arte de pesquisar: como fazer pesquisa qualitativa em Ciências Sociais. 8. ed. Rio de Janeiro: Record, 2004. 107 p.

GOOGLE DOCS. Site de produção, edição e colaboração de documentos. Disponível em: <https://docs.google.com/document/u/0/>. Acesso em: 10 nov. 2016.

GOOGLE MAPS. Site de visualização de mapas. Disponível em: <https://maps.google.com.br>. Acesso em: 10 nov. 2016.

IMBERNÓN, F. Formação docente e profissional: formar-se para a mudança e a incerteza. 9. ed. São Paulo: Cortez, 2011. 127 p. (Coleção questões da nossa época, 14).

JONASSEN, D. H. Design Problems for Secondary Students. National Center for Engineering and Technology Education. Logan: NCTE-NFS, 2011. Disponível em: <http://files.eric.ed.gov/fulltext/ED537388.pdf>. Acesso em: 7 abr. 2016.

Learning to Solve Problems: An Instructional Design Guide. Essential resources for training and HR professionals. San Francisco: Pfeiffer, 2003. 209 p.

KOEHLER, M. J. et al. The Technological Pedagogical Content Knowledge Framework for Teachers and Teacher Educators. Commonwealth Educational Media Centre for Asia. New Delhi: ICT Integrated Teacher Education - A Resource Book, 2013. Disponível em: <http://www.matt-koehler.com/publications/Koehler_et_al_2013.pdf>. Acesso em: 10 mar. 2016.

KOEHLER, M. J.; MISHRA, P. Teachers learning technology by design. Journal of Computing in Teacher Education, U.S., v. 21, n. 2, p. 94-102, 2005.

MACHADO, N. J. D'AMBROSIO, U.; ARANTES; V. A. Parte III: Entre pontos e contrapontos. In: ARANTES; V. A. (Org.). Ensino de matemática: pontos e contrapontos. São Paulo: Summus, 2014. p. 123-148.

MISHRA, P.; KOEHLER, M. J. Technological pedagogical content knoledge: A framework for teacher knowledge. Teachers College Record, New York, DF, v. 108, n. 6, p. 1017-1054, june 2006.

MISKULIN, R. G. S. As possibilidades didático-pedagógicas de ambientes computacionais na formação colaborativa de professores de matemática. In: FIORENTINI, D. Formação de Professores de Matemática: explorando novos caminhos com outros olhares. Campinas: Mercado das Letras, 2003. p. 217-247.

MIZUKAMI, M. das G. N. Aprendizagem da docência: conhecimento específico, contextos e práticas pedagógicas. In: NACARATO, A. M.; PAIVA, M. A. V. (Org.). A formação do professor que ensina matemática: perspectivas e pesquisas. 1. ed. Belo Horizonte: Autêntica, 2008. p. 213-231. 
NCTM. De los princípios a la acción: para garantizar el éxito matemático para todos. México, DF: 2014.

ONUCHIC, L. de la R.; ALLEVATO, N. S. G. Pesquisa em Resolução de Problemas: caminhos, avanços e novas perspectivas. Bolema, Rio Claro, v. 25, n. 41, p. 73 - 98, 2011.

ONUCHIC, L. de la R.; MORAIS, R. dos S. Resolução de problemas na formação inicial de professores de Matemática. Educação Matemática Pesquisa, São Paulo, v. 15, n. 3, p. 671691, 2013.

PAIS, L. C. Ensinar e aprender Matemática. 2. ed. Belo Horizonte: Autêntica, 2013. 151 p.

PEREZ, G. Prática reflexiva do professor de Matemática. In: BICUDO, M. A. V.; BORBA, M. C. (Org.). Educação Matemática: pesquisa em movimento. 4. ed. São Paulo: Cortez, 2012. p. 272-286.

PERRENOUD, P. A formação dos professores no Século XXI. In: PERRENOUD, P. THURLER, M. G. As competências para ensinar no século XXI: a formação dos professores e o desafio da avaliação. Porto Alegre: Artmed, 2002. p. 11-33.

PONTE, J. da. Tecnologias de Informação e Comunicação na Formação de Professores: Que Desafios? Revista Iberoamericana de Educación, [S.I.], v. 24, n. 3, p. 63-90, set./dez. 2000.

POZO, J. I. (Org.). A solução de problemas: aprender a resolver, resolver para aprender. Porto Alegre: Artmed, 1998. 177 p.

RICHIT, A. Projetos em Geometria Analítica usando software de Geometria Dinâmica: repensando a formação inicial docente em Matemática. 2005. 215f. Dissertação (Mestrado em Educação Matemática) - Instituto de Geociências e Ciências Exatas, Universidade Estadual Paulista Júlio de Mesquita Filho, Rio Claro, 2005.

ROSA, M. Cyberformação com professores de Matemática: interconexões com experiências estéticas na cultural digital. In: ROSA, M.; BAIRRAL, M. A.; AMARAL, R. B. (Org.). Educação Matemática, Tecnologias Digitais e Educação a Distância: pesquisas contemporâneas. São Paulo: Livraria da Física, 2015. p. 57-96.

SCHÖN, D. A. Educando o profissional reflexivo: um novo design para o ensino e a aprendizagem. Porto Alegre: Artmed, 2000. 256 p.

SHULMAN, L. S. Conhecimento e ensino: fundamentos para a nova reforma. Cadernos Cenpec, São Paulo, v. 4, n. 2, p. 196-229, dez. 2014.

Submissão: 29/11/2016

Aceite: 04/05/2017 